\title{
Knowledge Management System Untuk Meningkatkan Kualitas Tenaga Kerja
}

\author{
Mukhammad Khoirullah $^{1}$, Yuni Sugiarti ${ }^{2}$, Nia Kumaladewi ${ }^{3}$
}

\begin{abstract}
Abstrak-Sharing knlwedge merupakan komponen penting dalam meningkatkan kualitas. Namun dalam pelaksanaan di Badan Nasional Penempatan dan Perlindungan Tenaga Kerja Indonesia (BNP2TKI), sharing knowledge menjadi bermasalah ketika yang digunakan masih dilakukan secara manual yaitu dengan bertatap muka dalam pelaksanaannya sehingga, menyebabkan kesulitan bagi pegawai maupun TKI dalam mengimplentasikannya selain itu terdapat redudansi data dalam setiap responnya dan publikasi knowledge yang tidak teratur. Tujuan dari penelitian ini adalah untuk menghasilkan Knowledge Management System (KMS) yang dapat membantu pegawai dan TKI dalam melakukan sharing knowledge agar memperoleh data atau informasi sesuai kebutuhan yaitu dengan menyediakan dokumen, video, berita dan layanan diskusi guna memenuhi kebutuhan KMS. Metode pengumpulan data yang digunakan adalah observasi, wawancara, studi pustaka, untuk pengembangan sistem metode yang digunakan Rapid Application Development (RAD) sedangkan dalam pengimplementasian KMS menggunakan Knowledge Management Process, serta perancangan KMS menggunakan pemodelan Unified Modeling Language (UML). Bahasa pemrograman yang digunakan dalam membangun sistem adalah $P H P$ dan $M y S Q L$. Hasil dari penelitian ini adalah sebuah sistem yang dapat memudahkan sharing knowledge antar pegawai BNP2TKI dan TKI agar mendukung peningkatan kualitas TKI.
\end{abstract}

Keywords-Knowledge Management System, Sharing Knowledge, Tenaga Kerja Indonesia.

\section{Pendahuluan}

$\mathrm{T}$ eknologi informasi begitu pesat berkembang dan dampaknya telah kita rasakan. Berbagai kemudahan yang kita terima, seperti kemudahan untuk memperoleh informasi melalui telepon seluler dan internet, kemudahan dalam bertransaksi dengan menggunakan kartu kredit atau kartu debit, dan kemudahan untuk mengambil uang melalui Anjungan Tunai Mandiri (ATM), adalah berkat kemajuan teknologi informasi [1].

Dalam mengikuti pertumbuhan suatu informasi, tentu tidak hanya langsung menerapkannya tetapi harus melalui adanya

Received: 4 Mei 2018; Revised: 12 Juli 2020; Accepted: 14 Juli 2020

${ }^{1}$ M. Khoirullah., Program Studi Sistem Informasi, Fakultas Sains dan Teknologi, Universitas Islam Negeri Jakarta, Indonesia (e-mail: khoirullah@live.com)

http://journal.uinjkt.ac.id/index.php/aism suatu proses pengolahan serta pemanfaatan dari informasi yang ada. Agar sebuah informasi menjadi sesuatu yang bernilai, kemudian tumbuh menjadi sebuah pengetahuan didalam organisasi atau perusahaan, maka dibutuhkannya suatu sistem atau konsep yang dikenal dengan Knowledge Management (KM). Melalui konsep ini, dapat membantu sebuah organisasi ataupun perusahaan agar tidak perlu mengeluarkan hal yang lebih untuk menghadapi suatu tingkat persaingan dengan kompetitornya serta menciptakan suatu inovasi baru untuk produk atau jasa yang dimiliki [2].

BNP2TKI sebagai lembaga pemerintahan non kementrian bertugas untuk melakukan penempatan atas dasar perjanjian secara tertulis antara pemerintah dengan pemerintah negara pengguna TKI atau berbadan hukum di negara tujuan penempatan, serta memberikan pelayanan dan pengkoordinasian terhadap para calon TKI. Dalam penerapannya saat ini, KM yang terjadi yaitu pihak operator dari BNP2TKI mengumpulkan dokumen-dokumen knowledge yang telah disetujui oleh validator lalu mereka mempublikasikannya ketika pembekalan. Adapun ketika TKI menginginkan knowledge baru yang belum ada mereka harus bertatap muka kembali ataupun me-request-nya melalui media lain, setelah itu operatorpun meresponnya sesuai dengan request setelah diajukan dan disetujui oleh validator dengan pengajuan secara bertatap muka dengan membawa hardcopynya selain itu operatorpun dapat mempublikasikannya dengan cara menghubungi TKI yang bersangkutan. Selain itu adapun request TKI yang datang berulang-ulang kali dengan beberapa request yang sama dan menyita waktu bagi operator untuk meresponnya yang juga berulang-ulang kali dengan perihal yang sama, serta tidak adanya sistem yang mendukung untuk menampung knowledge yang dimiliki satu sama lain, mendukung pengajuan validasi serta mendukung penggunduhan file-file tanpa harus membuka atau menggunakan banyak aplikasi atau media.

Untuk berbagai masalah diatas KMS menjadi salah satu solusi untuk membantu pengolahan pengetahuan, sarana KMS dapat dimanfaatkan untuk sharing knowledge, dimana seorang TKI memiliki account pribadi dan BNP2TKI dapat mempublikasikan file baik berbentuk dokumen, gambar maupun video, bahkan file sebagai acuan bagi para TKI,

\footnotetext{
${ }^{2}$ Y. Sugiarti, Program Studi Sistem Informasi, Fakultas Sains dan Teknologi, Universitas Islam Negeri Jakarta, Indonesia (e-mail: yuni.sugiarti@uinjkt.ac.id)

${ }^{3}$ N. Kumaladewi, Program Studi Sistem Informasi, Fakultas Sains dan Teknologi, Universitas Islam Negeri Jakarta, Indonesia (e-mail: nia.kumaladewi@uinjkt.ac.id)
} 
sehingga para TKI dapat memiliki pengetahuan yang sama, kemudian dengan pengetahuan tersebut diharapkan dapat meningkatkan kualitas mereka.

Dari latar belakang tersebutlah penulis mengusulkan perancangan dan pembangunan KMS. Penulis sendiri merupakan mahasiswa Jurusan Sistem Informasi, Fakultas Sains dan Teknologi, Universitas Islam Negeri Syarif Hidayatullah Jakarta, melangsungkan penelitiannya pada bidang analisis perancangan serta rancang bangun KMS dan mengambil judul "Rancang Bangun Knowledge Management System untuk Meningkatkan Kualitas Tenaga Kerja" yang dilakukan di BNP2TKI

\section{II.LITERATURE REVIEW}

Beberapa penelitian mengenai Knowledge Management System termasuk penelitian dengan judul "Designing Knowledge Management Systems at Bina Nusantara IT using Blogs, Wikis, Forums and Documents [3]" yang Mengelompokkan pengetahuan ke dalam Blog, Wiki, Forum, dan Dokumen untuk mempermudah menemukan pengetahuan dan mempersingkat waktu yang dibutuhkan untuk menemukan solusi untuk suatu masalah. "Perancangan Knowledge Management System Layanan Perbaikan Motor Pada PT XYZ[4]" melengkapi aplikasi dengan fitur pengetahuan Front Desk yang berguna untuk memahami seputar layanan perbaikan motor. "Penerapan Knowledge Management System (KMS) Berbasis Web Studi Kasus Bagian Teknisi dan Jaringan Fakultas Ilmu Komputer Universitas Sriwijaya[6]' membuat Sistem berbasis web yang memudahkan para karyawan mengakses dimana saja dan kapan saja dan memiliki koneksi ke internet untuk mempermudah karyawan dalam sharing knowledge. " Implementasi Knowledge Management System Berbasis Semantic Mediawiki pada divisi Operasional perusahaan telekomunikasi[10]" membuat implementasi Knowledge Management System dengan Penerapan basis semantic mediawiki pula mempercepat kinerja dalam pengaksesan setiap halamannya dan penggunaan jaringan local area network untuk mempercepat kinerja kms. "Model Knowledge Management System Dengan Teknologi Cloud Computing [7]' membuat implementasi knowledge management system dengan teknologi cloud computing dapat mempercepat proses. Jika perusahaan membuka cabang baru untuk melayani contact center outsourcing. Selain itu perusahaan dapat menghemat biaya, karena cabang yang baru dibuka tersebut tidak perlu lagi menyediakan komputer server untuk implementasi KMS.

Pada penelitian ini penulis merancang dan membangun sebuah KMS dengan beberapa keunggulan antara lain:

1) KMS yang dibangun didukung dengan penglompokan knowledge yaitu dokumen, berita dan diskusi agar mempermudah dan mempersingkat waktu dalam menemukan knowledge.

2) KMS inipun dilengkapi dengan laporan publikasi knowledge guna menjadi evaluasi bagi BNP2TKI serta dilengkapi front-end bagi TKI.

3) Sistem ini dibangun agar pengguna dapat langsung menggunakannya tanpa perantara aplikasi lainnya, sehingga otoritas data yang terjaga, serta menghasilkan informasi- informasi yang berkaitan dengan data yg diperlukan secara tepat, sedangkan jika penggunaan aplikasi lain seperti whatsapp salah satunya, otorisasi data yang tak terjamin serta data yang dihasilkan sifatnya jadi bebas dan banyak yang pembahasannya di luar tema.

\section{METODOLOGI}

Penelitian ini melalui beberapa tahapan yang diawali dengan observasi untuk mendapatkan informasi yang dilanjutkan dengan identifikasi dan perumusan masalah, hingga akhirnya interpretasi hasil dan didapatkan kesimpulan. Gambar 1. Menunjukan secara spesifik prosedur penelitian yang peneliti gunakan sebagai penuntun dasar pada tahapan penelitian. Adapun metode pengembangan sistem yang digunakan yaitu Rapid Application Development.

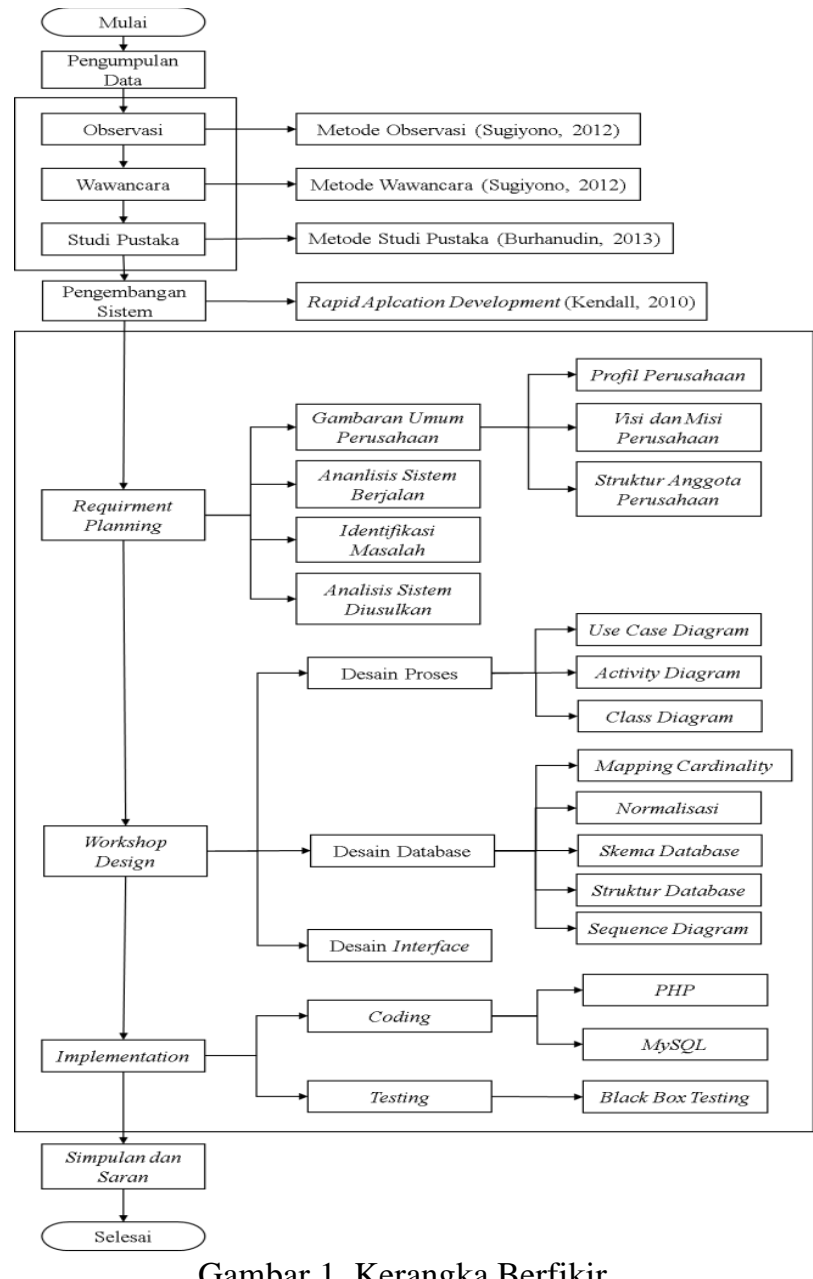

IV. HASIL DAN PEMBAHASAN

\section{A. REQUIREMENT PLANNING}


Pada tahap ini dilakukan pendefinisian kebutuhan penelitian dan dari pendefinisian tersebut akan menampilkan hasil dari gambaran umum perusahaan seperti struktur anggota BNP2TKI. Tercantum dalam Gambar 2.

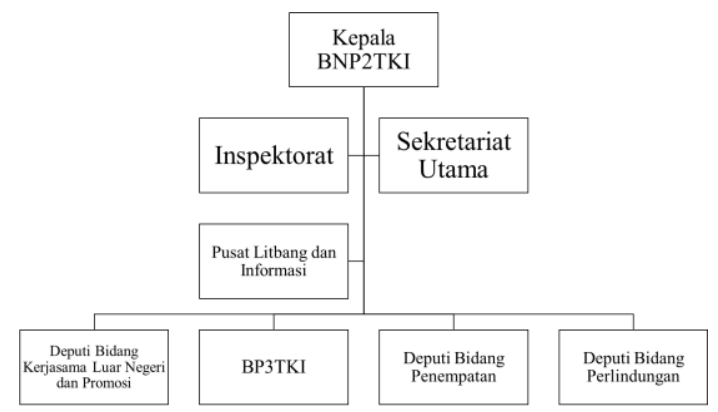

Gambar 2. Stuktur Organisasi BNP2TKI [9]

Seperti yang telah dipaparkan sebelumnya pada pendahuluan tentang alur sistem yang terjadi maka setelah mengetahui sistem yang berjalan pada BNP2TKI maka penulis mengusulkan sistem yang akan dibangun, dengan gambaran seperti di bawah ini.

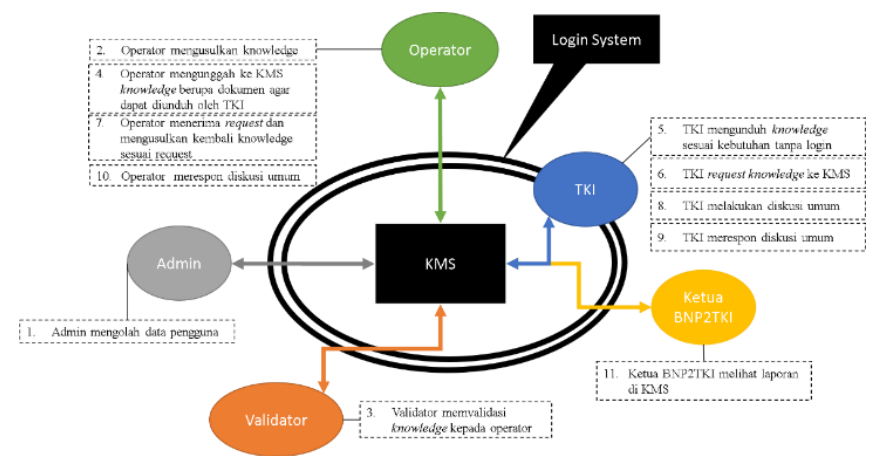

Gambar 3. Rich picture sistem usulan

\section{B. WORKSHOP DESIGN}

Tahapan ini merupakan tahapan lanjutan dari sistem yang diusulkan dari tahapan sebelumnya, dimana pada tahap ini dibuat beberapa desain sistem baik dari desain proses, desain database hingga desain interface.

\section{1) Desain Proses}

Pada desain proses penulis merancang alur sistem dengan menggambarkan diagram-diagram yaitu:

\section{a. Use Case Diagram}

Untuk diagram ini menggambarkan interaksi aktor pada proses bisnis, untuk diagram ini penulis gambarkan seperti gambar di bawah ini.

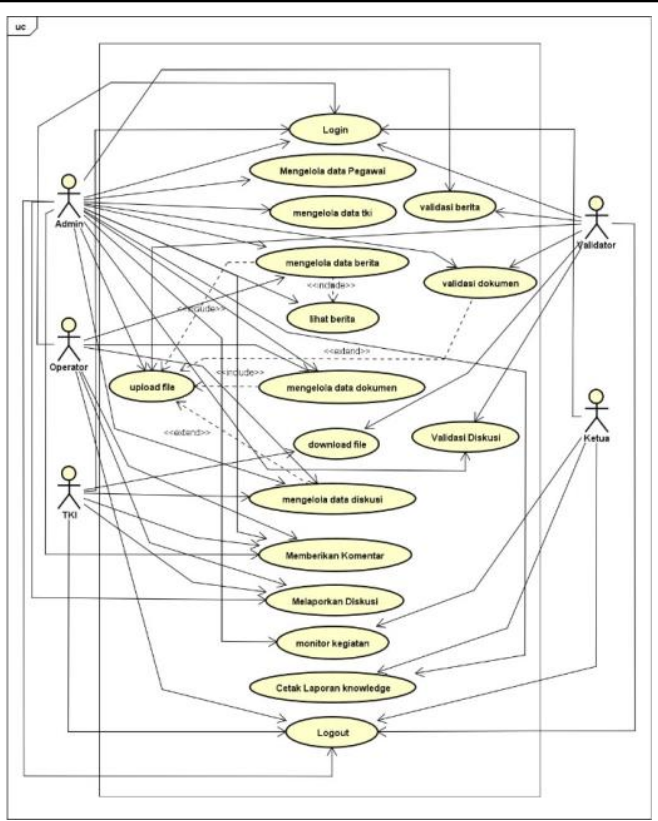

Gambar 4. Use Case Diagram

b. Activity Diagram

Untuk diagram ini menggambarkan aktifitas proses bisnis, untuk diagram ini penulis gambarkan salah satunya seperti gambar di bawah ini.

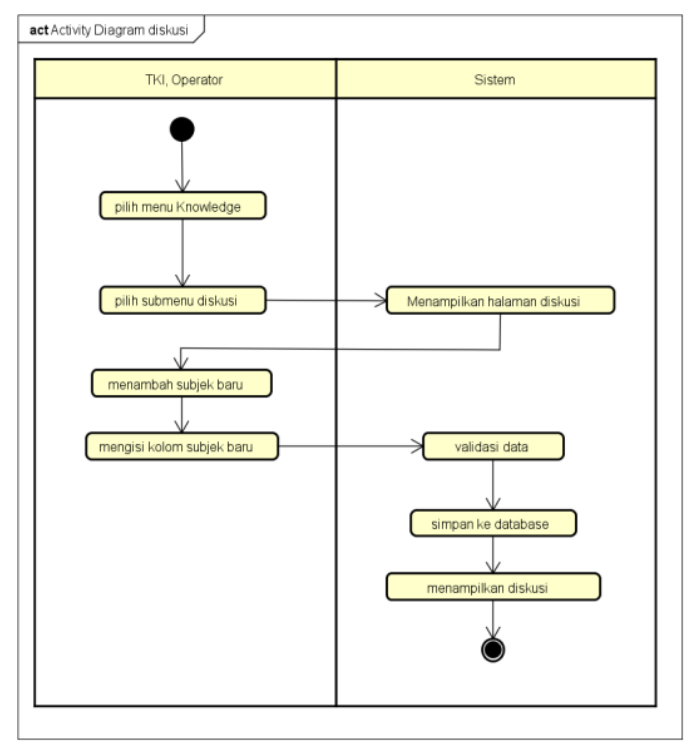

Gambar 5. Activity Diagram

\section{c. Class Diagram}

Untuk diagram ini menggambarkan kelas-kelas yang terjadi dalam proses bisnis, untuk diagram ini penulis gambarkan salah satunya seperti gambar di bawah ini. 


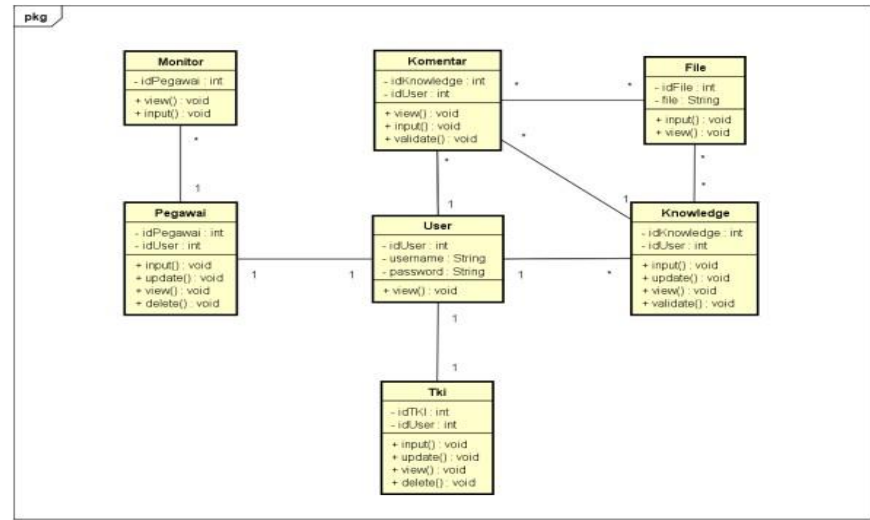

Gambar 6. Class Diagram

2) Desain Database

Pada desain database penulis merancang database KMS, seperti dibawah ini:

a. Mapping Cardinality

Tahap ini merupakan bagian dari pemetaan kelas- kelas yang telah didapat, untuk gambarnya dibawah ini: $p k_{0}$

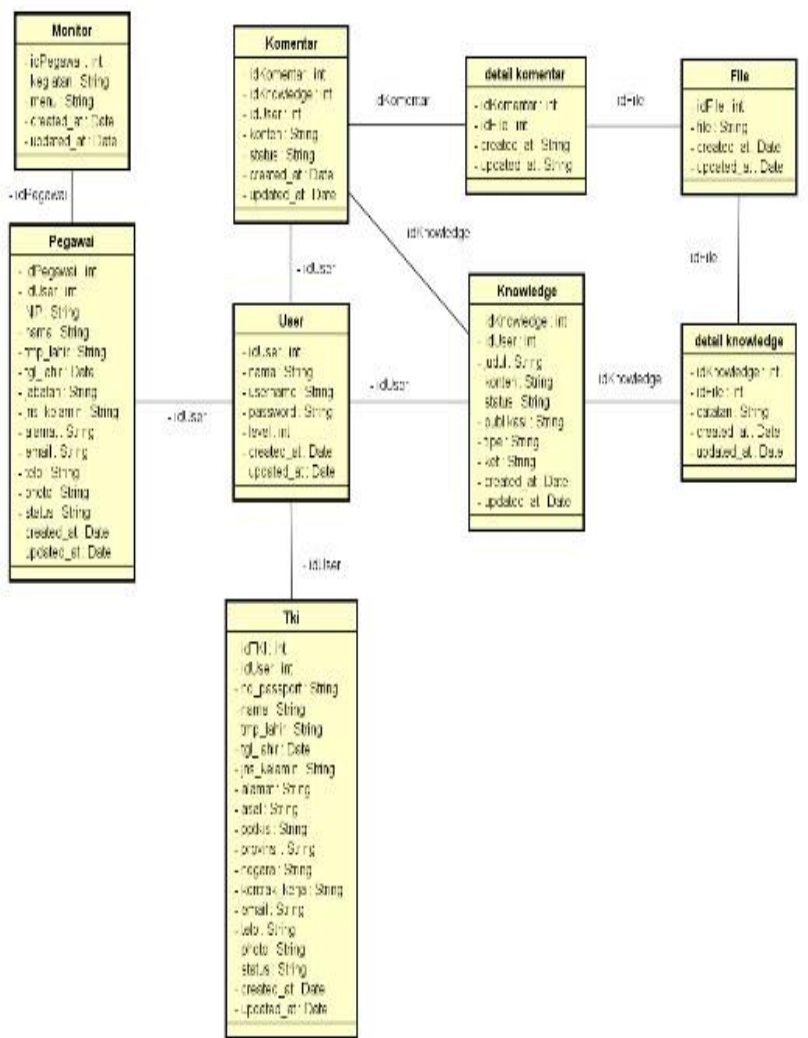

Gambar 7. Mapping Cardinality

b. Normalisasi

Untuk normalisasi sendiri penulis menormalisasi tabel hingga $3 \mathrm{NF}$, untuk tabel-tabel tersebut ada 9 tabel, yaitu:

- Tabel User

- Tabel Pegawai

- Tabel Monitor

- Tabel TKI

- Tabel Knowledge

- Tabel Komentar

- Tabel File

- Tabel Detail Knowledge

- Tabel Detail Komentar

- Tabel Detail Knowledge

- Tabel Deta

c. Skema Database

Setelah didapat tabel-tabel yang telah normal maka, dibuatlah skema seperti gambar dibawah ini: 


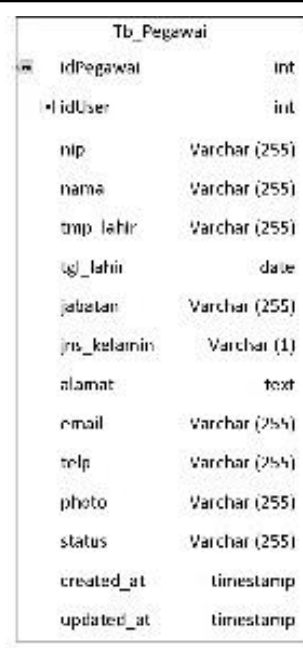

\begin{tabular}{|c|c|}
\hline \multicolumn{2}{|c|}{ Tis Ploritur } \\
\hline 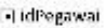 & int \\
\hline kegiatan & Varchar (2.5.5! \\
\hline menu & Varchar i255j \\
\hline created at & timestarnp \\
\hline uptabet_al & Limeslamp \\
\hline
\end{tabular}

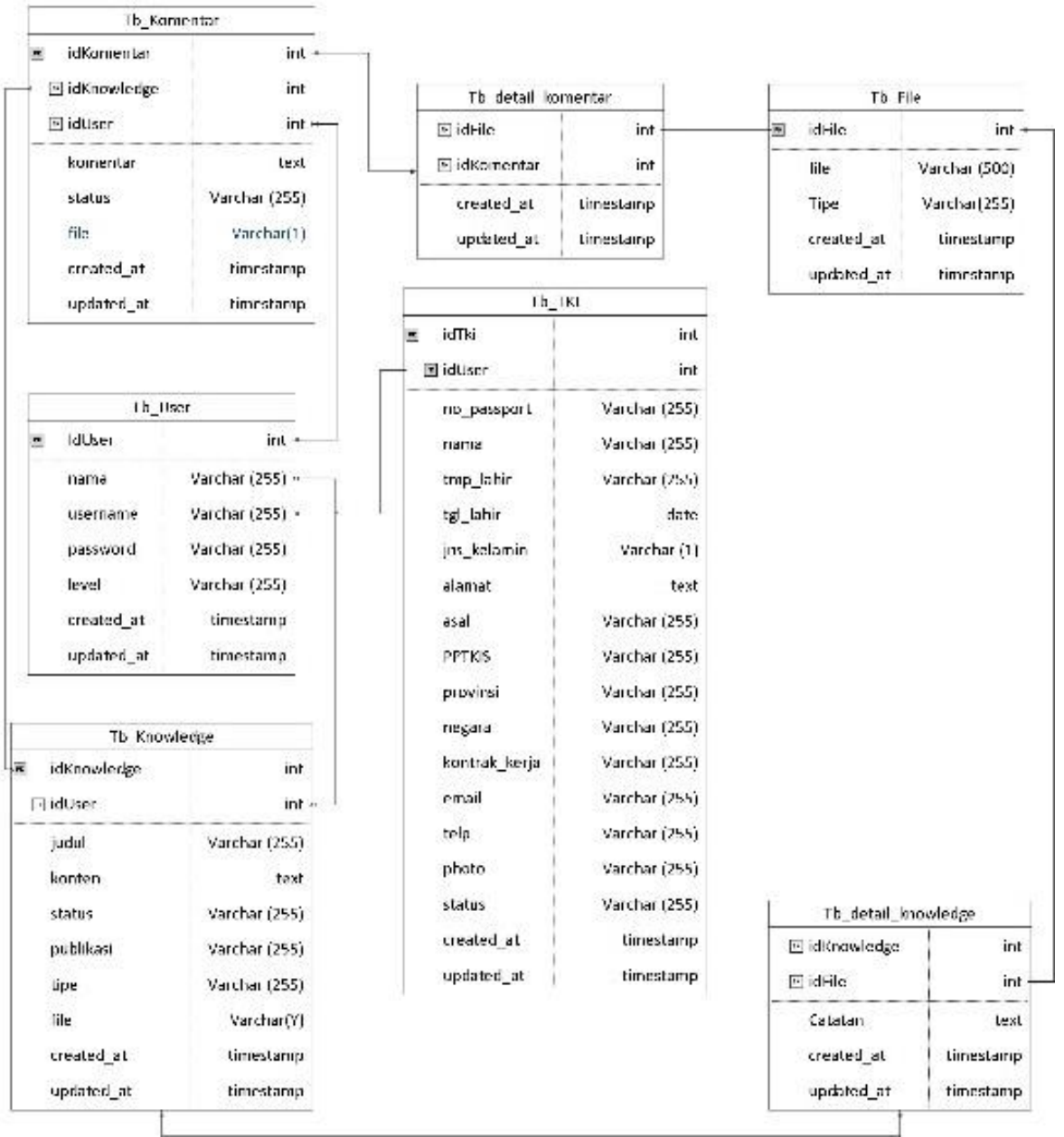

Gambar 8. Skema Database

\section{d. Spesifikasi Database}

Dari skema yang dibuat maka dibuat spesifikasi untuk tiap tabelnya, dimana tabel-tabel tersebut sesuai yang dengan tabel yang telah didapat, salah satunya seperti tabel dibawah ini:

- Nama Tabel : Tb_Knowledge Jenis Tabel : Tabel Transaksi Primary key: idKnowledge

Tabel 1.

Spesifikasi untuk Tabel Knowledge

\begin{tabular}{|c|c|c|c|c|c|}
\hline No & Nama & Tipe Data & Length & Index & Keterangan \\
\hline 1 & Idknowledge & Int & 10 & PK & $\begin{array}{l}\text { Atribut kunci } \\
\text { agar data } \\
\text { knowledge } \\
\text { data dibaca } \\
\text { di tabel lain }\end{array}$ \\
\hline 2 & Iduser & Int & 10 & FK & $\begin{array}{l}\text { Atribut kunci } \\
\text { yang } \\
\text { memiliki } \\
\text { relasi kepada } \\
\text { tabel } \\
\text { user }\end{array}$ \\
\hline 3 & Judul & Varchar & 50 & & $\begin{array}{l}\text { Judul } \\
\text { knowledge }\end{array}$ \\
\hline
\end{tabular}

\begin{tabular}{|c|c|c|c|c|}
\hline 4 & Konten & Text & & $\begin{array}{l}\text { Konten } \\
\text { knowledge }\end{array}$ \\
\hline 5. & Status & Varchar & 1 & $\begin{array}{l}\text { Staus } \\
\text { Knowledge }\end{array}$ \\
\hline 6. & Publikasi & Varchar & 1 & $\begin{array}{l}\text { Status } \\
\text { Publikasi } \\
\text { Knowledge }\end{array}$ \\
\hline 7. & Tipe & Carchar & 1 & $\begin{array}{l}\text { Tipe } \\
\text { Knowledge } \\
\text { Keterangan } \\
\text { tentang }\end{array}$ \\
\hline 8. & File & Varchar & 1 & $\begin{array}{l}\text { memiliki atau } \\
\text { tidak memiliki } \\
\text { file dalam } \\
\text { knowledge }\end{array}$ \\
\hline 9. & Created_At & Timestamp & & $\begin{array}{l}\text { Waktu } \\
\text { penginputan }\end{array}$ \\
\hline 10. & Update_At & Timestamp & & $\begin{array}{l}\text { Waktu } \\
\text { perubahan }\end{array}$ \\
\hline
\end{tabular}

e. Sequence Diagram

Setelah alur proses bisnis beserta database-nya sudah didapat, maka dilanjutkan untuk membuat sequence diagram, seperti Gambar 9 dibawah ini: 


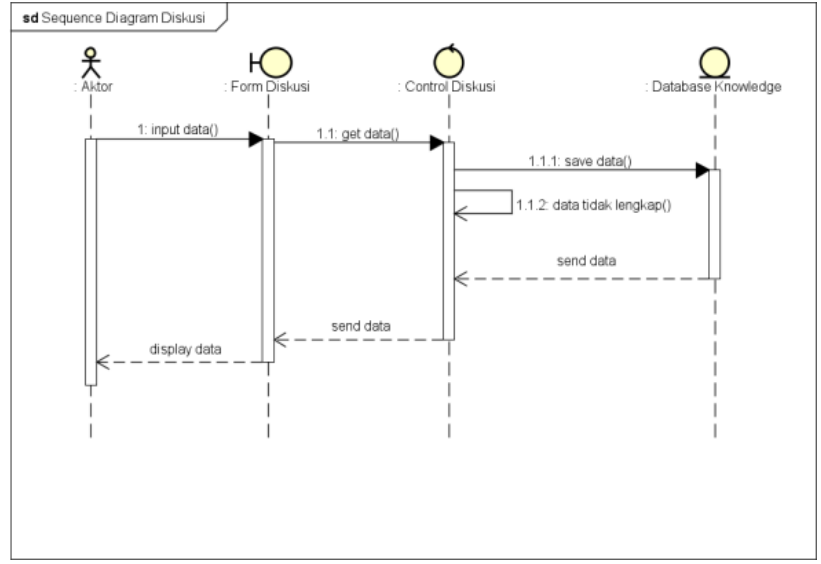

Gambar 9. Squence Diagram

3) Desain Interface

Setelah melakukan tahap desain proses dan desain database penulis melanjutkan desain interface. Pada desain ini penulis merancang interface terdiri dari 5 menu yaitu:
a. Menu untuk Admin
b. Menu untuk Validator
c. Menu untuk Operator
d. Menu untuk Ketua
e. Menu untuk TKI

Adapun gambaran interface yang dirancang menjadi 2 bagian yaitu:

\section{a. Back-End}

Untuk back-end ini merupakan interface yang digunakan oleh para pengguna yang merupakan bagian dari pegawai BNP2TKI, untuk gambarnya sendiri seperti dibawah ini:

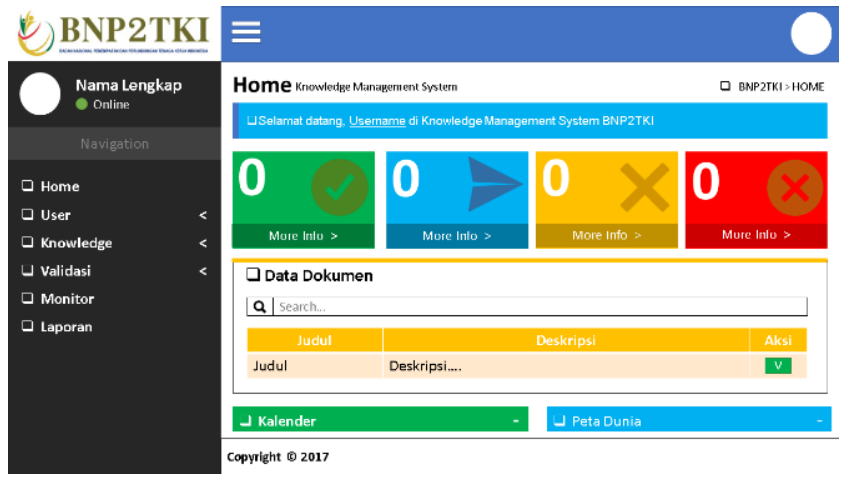

Gambar 10. Back End untuk Home

\section{b. Front-End}

Untuk front-end ini merupakan interface yang digunakan oleh para Tenaga Kerja Indonesia, untuk gambarnya sendiri seperti dibawah ini:

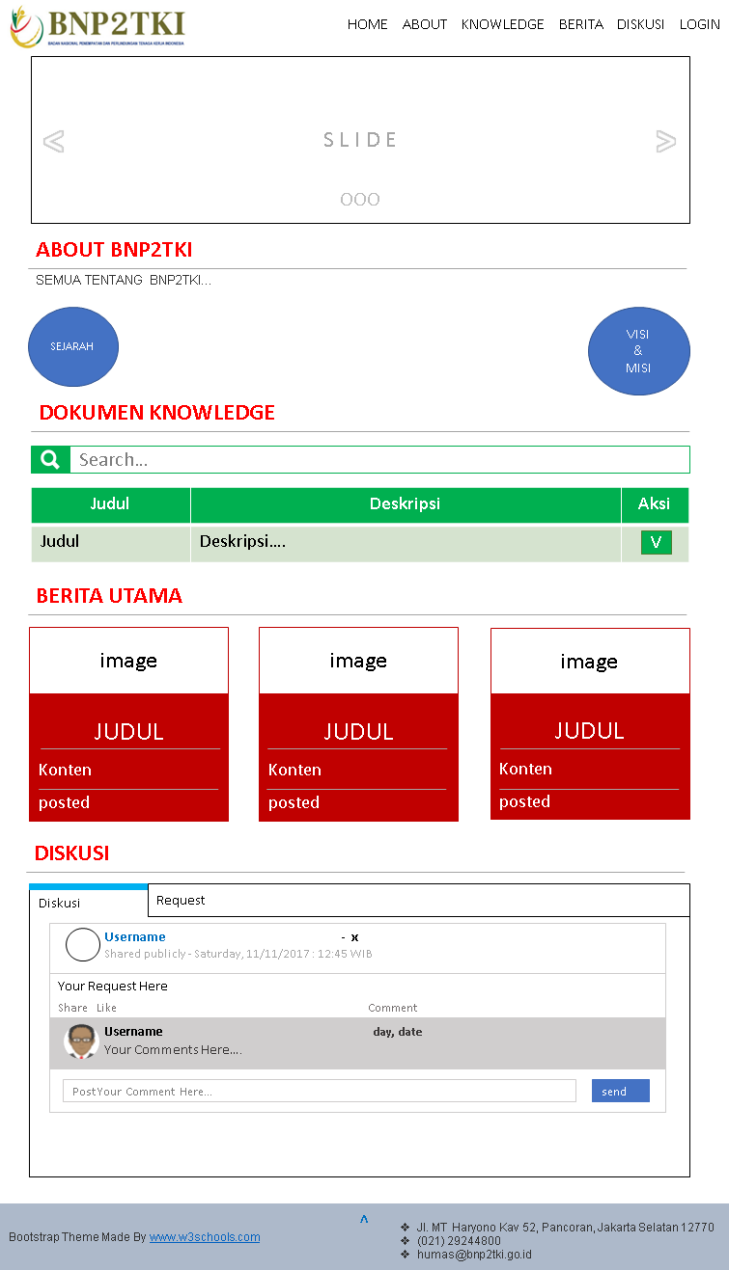

Gambar 11. Front End untuk Home

\section{Implementasi}

Implementasi sistem adalah fase lanjutan setelah melakukan workshop design. Tahap yang dikerjakan pada fase implementasi ini antara lain melakukan pengkodean untuk membangun sebuah perangkat lunak, serta menjelaskan mengenai arsitektur fisik untuk hardware dan software dalam sistem. Setelah paket perangkat lunak selesai dibuat, maka tahap berikutnya adalah pengujian sistem menggunakan Blackbox Testing.

\section{V.KESIMPULAN}

Berdasarkan uraian dan pembahasan pada bab-bab sebelumnya, maka dapat disimpukan bahwa:

A. Sistem ini dapat diakses secara langsung guna membantu antara BNP2TKI ke TKI serta antar TKI dalam sharing knowledge dengan otomatis tidak mengharuskan mereka bertatap muka.

B. Sistem ini dapat mengelola knowledge secara menyeluruh dan teratur walaupun terjadi perbedaan knowledge diantara TKI dan BNP2TKI dari segi data, informasi serta dokumen-dokumen yang didapat dan pengalaman, pemikiran juga kompetensi setiap individunya.

C. Menghindari terjadinya redudansi data dalam merespon request atau pertanyaan dari para TKI kepada pegawai 


\section{BNP2TKI.}

D. Pada KMS ini terdapat beberapa kelebihan dan kekurangan.

1) Kelebihan:

- Penelitian KMS ini tidak hanya berupa perancangan tetapi juga dibangun dengan menggunakan bahasa pemrograman PHP dan didukung dengan MYSQL sebagai database.

- Penelitian ini memiliki desain perancangan agar dapat mempermudah pengembangan sistem untuk selanjutnya.

- KMS yang dibangun didukung dengan penglompokan knowledge yaitu dokumen, berita dan diskusi agar mempermudah dan mempersingkat waktu dalam menemukan knowledge.

- KMS inipun dilengkapi dengan laporan publikasi knowledge guna menjadi evaluasi bagi BNP2TKI serta dilengkapi front-end bagi TKI.

b. Kekurangan

- Belum diterapkannya sistem di dalam BNP2TKI hanya sampai tahap pengujian.

- Masih dijalankan di dalam localhost dan belum dihosting agar dapat dijalankan secara online.

- Validasi knowledge masih secara manual.

\section{REFERENSI}

[1] A. Kadir and T. C. Triwahyuni, Pengantar Teknologi Informasi, Yogyakarta: CV. ANDI, 2013.

[2] K. Dalkir, Knowledge Management in Theory and Practice, USA : The MIR Press, 2011.

[3] K. Iskandar, Tony, C. H. Phankova and W. Agustino, "Perancangan Knowledge Management System Pada It Bina Nusantaramenggunakan Blog, Wiki, Forum Dan Document," ComTech, vol. V, no. 1, p. 13, 2014.

[4] A. Alinto and Yulianti, "Perancangan Knowledge Management System Layanan Perbaikan Motor Pada Pt Xyz," p. 10, 2015.

[5] S. Darudiato and K. Setiawan, "Knowledge Management: Konsep dan Metodologi," ULTIMA InfoSys, vol. IV, no. 1, p. 7, 2013.

[6] W. K. Sari and K. D. Tania, "Penerapan Knowledge Management System (KMS) Berbasis Web Studi Kasus Bagian Teknisi dan Jaringan
Fakultas Ilmu Komputer Universitas Sriwijaya," Jurnal Sistem Informasi (JSI), vol. VI, no. 2, p. 8, 2014.

[7] Haris and J. S. Lusa, "Model Knowledge Management System Dengan Teknologi Cloud Computing," p. 7, 2016.

[8] A. . E. Wijaya, "KNOWLEDGE MANAGEMENT SYSTEM MODEL PADA FORUM DISKUSI PETANI BUAH NAGA MENGGUNAKAN CMS Phpbb," Jurnal Teknologi Informasi dan Ilmu Komputer (JTIIK), vol. 4, no. 1, p. 8, 2017.

[9] BNP2TKI, "BNP2TKI," Lampiran PER. 10/KA/IV/2012 BNP2TKI, 20 April 2012. [Online]. Available: http://www.bnp2tki.go.id/frame/9026/Struktur-OrganisasiBNP2TKI.html.

[10] I. k. Virdaus, "Implementasi Knowledge Management System Berbasis Semantic Mediawiki pada divisi Operasional perusahaan telekomunikasi," Technology, p. 8, 2011. 
